\title{
The Discussion on Music Listening Teaching in College
}

\author{
Zhengchang Zhou ${ }^{1, \text { a }}$ \\ ${ }^{1}$ Music and Dance Institute of Qujing Normal College \\ hunter2011@foxmail.com
}

Keywords: College, Music Listening Teaching

\begin{abstract}
Music listening teaching of common high school has been a hotspot topic of the concerning people and they also gain a lot of mature experience up to now. But, because of the music education of common high school started late, it is lack of some scientific experience about the positioning of the entire music appreciation, teaching content, teaching methods and means, etc.Music appreciation has been a very popular elective course among the students in colleges and universities since the begining, it plays a very important role in terms of improving the quality of students. So we should pay attention on it and only in this way can it play a better role in achieving target of college quality education.
\end{abstract}

\section{Introduction}

Music appreciation class as a cultural quality education in university, it is an important component of universal ease of operation, it is one of the best ways to implement music education in colleges and universities. Music education objectives in college unlike professional music education. Its main task is through art courses and carrys out a variety of extra-curricular arts and cultural activities, cultivate and improve students' aesthetic ability and attainment. And the object of education and other subjects from the University of different, there are electives students, art students, correspondence students divided into three levels, basic music is uneven, also different disciplines. Levels of training target specificity and education objects, determines the music appreciation courses need to have a reasonable positioning and planning. Currently, the courses are still some issues to be discussed in the textbooks, teaching methods and teaching methods, curriculum evaluation mechanism, enhance the quality of teachers [1].

\section{The Optimization of Materials Selection and Teaching Content}

Select the best materials. In order to ensure quality teaching materials, use the national general and recognized quality teaching universities is particularly important. For example, the National College of outstanding teaching award of the Ministry of Education for the 21st Century course, included in the "general higher education textbook construction and reform plan" focused on planning materials or textbooks, textbooks recommended by the Ministry of Education, provincial and ministerial level teaching awards, newly published nearly three years and peers recognized outstanding teaching materials. Music appreciation class textbook should select the best from the major categories of textbooks, teaching teachers to strict quality control.

Study and process materials. As a basis for the implementation of curriculum materials and support, it is the basic material of curriculum resources. The focus lies in the development and utilization of research and processing materials. Currently teaching at the University of Music Appreciation on the general lack of multidisciplinary content penetration is not strong sense of the times, lack of continuity of knowledge and systematic enough and so on. Materials selected for further study, according to the actual needs of teaching in teaching certain content expansion, updates, breaking the limitations of textbooks, compensate for the lack of teaching materials, is necessary. 


\section{The Reform of Teaching Means and Teaching Methods}

Forms of teaching and teaching methods, not blindly deny tradition, but should at the appropriate retention and improve the traditional basis of efforts to explore the Knowledge - to multi-dimensional change, achieve financial skills, appreciation, combining live demonstrations Multi-dimensional Teaching. Students on a high level, but also to expand research teaching, to create conditions for students' independent development and improve the overall quality.

Form an integrated teaching methods to optimize the classroom. to have a significant impact on the history of music education have focused on teaching form of synthesis. Such as focusing on music and dance Orff pedagogy, comprehensive action, language; Dalcroze pedagogy focusing on each course itself in different forms of synthesis. At the beginning of this century, comprehensive teaching method is more common. Teaching in the form of comprehensive, can mobilize the students a variety of cognitive channels, to explore a variety of potential students, greatly enhance students' interest in learning [2].

Based on tradition and forward to modern. Extensive application of modern educational technology and the rapid development of network technology, the connotation and extension of curriculum and teaching materials undergoing tremendous change, human understanding, acquire knowledge of modes of learning pathways and methods They have undergone tremendous changes. In the traditional teaching methods, focus on imparting knowledge step by step, this is the superiority of traditional teaching methods, but also its limitations, music teacher should stand in the height of quality education, to look at the problem of university teaching music appreciation. Music appreciation class is necessary to enrich the students' knowledge, but also to guide students to grasp the thinking and research methods subjects, students need to leave space for thinking. In addition to the process of teaching the use of multimedia various audio and video, pictures, text and other documentation supporting teaching activities, teachers should mostly in the form of a short essay assignments, guiding students to the library, internet up to collect relevant information, and then come back to the classroom discussion; or the use of the campus network sites teacher after school for students to consolidate knowledge, to extend and expand. Cultivate their independence, creative thinking and the ability to use the available information to solve the problem.

The expansion of foreign exchange, the pursuit of teaching effectiveness. AC College Music Appreciation Course and other public art between classes is not in-depth exchanges between the school and other subjects professional insufficient, infrequent exchanges between the schools, and cultural exchanges between the domestic and the international community more scarce in foreign exchange on highlighting the relative autistic. This is not conducive to the art of music education itself running water flow is not conducive to social services, is not conducive to the overall development of the school. Music Education at the forefront of campus culture and the social culture, music appreciation class Colleges should actively carry out exchanges and cooperation with its outside areas, enhance inter-linkages and integrated curriculum, continue to absorb the latest achievements in the art of music, colleges and universities absorb natural sciences advanced achievements and experiences humanities and music professional colleges on teaching ideas, teaching methods, in order to steady flow of students to the social transfer and penetration of its spiritual, ideological.

The two sides of individualized teaching. In the development of Chinese higher education, teaching management institutionalization, standardization, it should be said has made great achievements in building science, advanced management mode, etc., but also brought some negative impact. For example, too much emphasis on the normative teaching arrangements, does not distinguish between background knowledge structure and it does not distinguish between discipline, does not distinguish between new and old teachers of the differences, the same requirements, the same standards. Some unnecessary dogma of the teachers' creativity, affect their enthusiasm. We have to mention is for students more individualized, called for the implementation of targeted education for students of different features. But the differences in teaching and the students not only in terms of plasticity, for the different characteristics of teachers, whether teaching that there is not it? 
For example, teachers can deep background knowledge to students' rationality, logic and research capabilities to start, conduct research teaching; operation, organization ability of teachers can carry out experimental teaching students the image as a whole, operating skills. Teachers should recognize differences, weaknesses, in unity, under the normative Looking diversity [3].

\section{The Quantified Indicators and Pluralistic Evaluation Form}

Since the concept of music education, educational objectives change will affect the evaluation of teaching, while proper evaluation will build teaching curriculum, changing the concept of education play a catalytic role. Based on the current general music education "establishment of pluralistic evaluation, evaluation forms, both concerned with the results, more emphasis on the process of the evaluation system of" trends in a dynamic process of teaching should strive to explore and improve the curriculum evaluation mechanism to promote the development of students, to improve the teaching of teachers.

Quantify the evaluation system of teaching methods. Teaching quality evaluation criteria, evaluation fuzzy teaching methods, teaching methods focus on the reform and development obviously inadequate. Evaluation, whether the book is still mainly billboards neat hierarchy is clear and the like; whether to integrate the frontier of knowledge, the introduction of their research, the specific method of diversification, personalization, etc. are mostly blank. The author believes that it is necessary to quantify the evaluation criteria of teaching methods, teaching methods evaluation criteria increase the certainty, operability, make teaching evaluation system towards three-dimensional, institutionalized and standardized development, build more evaluation system at all levels complete, more balanced development between.

The establishment of a comprehensive assessment and evaluation system of musical arts education. Establishment of a comprehensive assessment of musical arts education, evaluation system, from teaching workload, arts groups to guide the students to participate in school and community arts practice, student learning outcomes, academic research and other aspects of the establishment of appropriate indicators, evaluation College Musical Art teacher performance, aimed at mobilizing their professional education by a narrow change to the overall quality of education in the initiative and play a leading role.

The pluralism of evaluation form and diversity of combinations. Music aesthetic sensibility evaluation and theoretical knowledge evaluation of the combination, based on its evaluation of the ability to feel, can be taken orally analysis, write a short essay form to promote theoretical analysis capabilities. Formative assessment and summative assessment combined, focusing on the learning process and learning attitude of study, promote enthusiasm for learning to play. Answers can be classroom discussions, learning questionnaire, unit assignments, papers, etc. written feedback learning, formative assessment and summative assessment. Both know the students in the learning process of learning attitude and learning methods, and focus on the quality and extent of student learning objectives accomplished, to quantitative evaluation and qualitative evaluation of the combination of ways to make holistic learning assessment of students [4].

\section{Enhance the Quality of Teachers}

Improve education levels and professional quality. Faced with diverse disciplinary backgrounds Objects, comprehensive university music appreciation class music teacher requires not only a solid professional knowledge and ability, their own cultural heritage in terms of history, astronomy, geography, painting, architecture, etc. is also very important. Therefore, teachers should explore the awareness and ability to learn and constantly improve the level of education, to broaden the knowledge structure. At the same time, through training, visit the school and other methods to study music style hard skills, accumulated a wealth of concerts, repertoire. Actively expand various channels, to create conditions to enhance the professional and business qualities, artistic ability, performance ability and teaching skills. 
Strengthen academic exchanges. To contact the teaching of scientific research, teaching and services, and promote teaching; teaching also stimulate research, stimulate creativity, teaching and research complement teaching and research phase long. At the same time, we should strengthen academic exchanges, expand your horizons, to understand the art latest academic trends, is conducive to the development of new frontiers in research [5].

Take full advantage of IT and educational technology. Although in recent years the development of audio-visual teaching has been great, multimedia classroom equipment is also increasingly advanced and complete, but no modern teaching concepts, improve hardware conditions alone could not achieve the desired effect of teaching. IT application in the teaching process standpoint is that "the promotion of integration of information technology and curriculum, the progressive realization of teaching content presentation, student learning, teachers' teaching methods and student interaction mode change"; "full take advantage of information technology to provide a variety of teaching and learning environment and a favorable learning tool for students to learn and develop. "We should recognize the tremendous role of modern information technology, but also see its essence. Music teachers not only to master the multimedia technology, it is more important is to explore the point of integration of information technology and music education, should have the full development and utilization of network resources, multifaceted broaden the ability of music appreciation teaching the depth of the excavation. Only based on classroom needs, develop a reasonable instructional design, in order to fully maximize the advantages of information technology.

\section{Conclusion}

Music Appreciation education is not only one of the best ways to implement music education in colleges and universities and it is also one of the best ways to heritage the crystals of human culture and artistic. Music education has the characteristics of diversity and richness which other subjects of education cannot matc. How to take full use of the function of music in students' overall development to grasp the pulse of the times, focus on social change, deepen reform and improve teaching quality are the long-term issue which music educators need to explore.

\section{References}

[1] X.Zhang, The cohesion of music education and elementary education new music curriculum in the 21st century, J. People's Music, 5(2007) 46-47.

[2] C.Li, Reflections on the development of higher education in China art, J. Art Education. 11(2006) 26-30.

[3] C.Y.Wang, Strategies of traditional music education in universities, J. China Music Education. 12(2009) 56-58.

[4] J.X.Li, Aesthetic core of music education reform, J. Central Music Conservatory. 9(2009) 19-22.

[5] Y.X.Zhang, The important role of music education in quality education, J. Chinese Music. 4(2007) 129-132. 